Northwestern University School of Law Northwestern University School of Law Scholarly Commons

Faculty Working Papers

2011

\title{
The Limits of Constructivism: Can Rawls Condemn Female Genital Mutilation?
}

Andrew Koppelman

Northwestern University School of Law, akoppelman@law.northwestern.edu

\section{Repository Citation}

Koppelman, Andrew, "The Limits of Constructivism: Can Rawls Condemn Female Genital Mutilation?" (2011). Faculty Working Papers. Paper 19.

http://scholarlycommons.law.northwestern.edu/facultyworkingpapers/19 
Forthcoming, Review of Politics

The Limits of Constructivism:

Can Rawls Condemn Female Genital Mutilation?

Andrew Koppelman*

Constructivist political theory, championed most prominently by John Rawls, builds up a conception of justice from the minimal requirements of political life. It has two powerful attractions. It promises a kind of civic unity in the face of unresolvable differences about the good life. It also offers a foundation for human rights that is secure in the face of those same differences. The very parsimony that is its strength, however, deprives it of the resources to condemn some atrocities. Because it focuses on the political aspect of persons, it has difficulty cognizing violence done to those aspects of the person that are not political, preeminently the body. Constructivism thus can be only a part of an acceptable theory of justice.

Constructivism develops an account of human rights on the basis of a thin conception of the person and her needs, abstracting away from controversial conceptions of human flourishing, and then deduces basic rights from this thin conception. The hope is that these rights will remain robust whatever ends the actual people who comprise a society turn out to have. This strategy works well for some rights, notably the right to free speech. But people have urgent needs that go far beyond what is necessary to

* John Paul Stevens Professor of Law and Professor of Political Science, Northwestern University. Thanks to Marcia Lehr for research assistance, and to Bruce Ackerman, Ron Allen, Peter de Marneffe, Mary Dietz, Gerald Dworkin, Samuel Freeman, Richard Garnett, Jon Garthoff, Warren Ingber, Bonnie Honig, Richard Kraut, Tony Laden, Martha Nussbaum, Steven D. Smith, Charles Taylor, Keith Topper, Alexander Tsesis, Kim Yuracko, Catherine Zuckert, and audiences at the Midwest Faculty Seminar, the James Madison Program in American Ideals and Institutions at Princeton University, the Northwestern University Political Theory Colloquium, and the Northwestern University School of Law Faculty Workshop for comments on earlier drafts. I also benefited from the research of Ira Karoll. This article had its origins in conversations with the late John Rawls at Harvard in 1994-95 while I was a fellow at what is now the Safra Foundation Center for Ethics. I am grateful for his kindness and willingness to engage. This research was supported by the Northwestern University School of Law Summer Faculty Research Program and the Kathleen M. Haight Fund. 
exercise their moral powers or to participate in democratic dialogue.

I will focus on one extreme human rights case: the practice of female genital mutilation (FGM), which, I will bet that you agree, violates basic human rights. Doubtless Rawls was appalled by the practice. Yet his theory cannot generate a basis for condemning it. A satisfactory conception of human rights must draw upon some normative source beyond that offered by constructivism. This conclusion is reinforced by considering the work of another political liberal, Martha Nussbaum, who offers a more coherent basis for rejecting FGM. Nussbaum accomplishes this, I will show, only by silently abandoning constructivism.

How severe a problem is this for constructivism? It depends on what constructivism is understood to be attempting. If the aspiration is a justificatory structure from which a complete account of human rights can be deduced, then it fails. On the other hand, its attractions remain powerful if it is understood to articulate a political ideal, one which however competes with other ideals and so is of indeterminate strength and scope.

Part I lays out in outline the familiar political theory of Rawls, focusing on his specification of the basic liberties. Part II then tests Rawls against the case of FGM, and shows that his theory cannot generate a basis for condemning it. Part III considers possible rejoinders by Rawls. Part IV discusses the implications of the argument.

\section{Rawls's Constructivism}

Samuel Freeman has observed that the "overriding concern" of all of Rawls's work "is to describe how, if at all, a well-ordered society in which all agree on a public conception of justice is realistically possible."1 A wellordered society, for Rawls, "is a society all of whose members accept, and know that the others accept, the same principles (the same conception) of justice." ${ }^{2}$ The aim is a stable basis for mutually respectful political life in a society that is profoundly divided about comprehensive moral doctrines.

\footnotetext{
${ }^{1}$ Samuel Freeman, Justice and the Social Contract: Essays in Rawlsian Political Philosophy (0xford: 0xford University Press, 2007), 4. 2 John Rawls, "A Kantian Conception of Equality," in Samuel Freeman, ed., Collected Papers (Cambridge: Harvard University Press, 1999), 255.
} 
This aspiration is possible, Rawls argues, because people with different comprehensive conceptions can and should reach an "overlapping consensus" on the principles of political cooperation. In an overlapping consensus, they may disagree about the ultimate foundations of the political principles that govern them, but they agree upon the principles, those principles are moral ones, and they are affirmed on moral grounds. ${ }^{3}$

Political constructivism begins from a conception of free and rational persons, which Rawls thinks is implicit in modern democratic culture. It holds that "the principles of political justice (content) may be represented as the outcome of a certain procedure of construction (structure)."4 The parsimonious conception of persons and their needs in the original position, and the decision procedure modeled in A Theory of Justice, generates the two principles of justice.

The specific conception of justice that Rawls endorses, based on the idea of the original position, is designed to exclude from the outset controversial conceptions of the good. "Systems of ends are not ranked in value ${ }^{5}$ in the original position, because the parties do not know their conceptions of the good. Those conceptions of the good simply do not figure into reasoning about the justice of the basic structure of society.

The exclusion of conceptions of the good shapes Rawls's position with respect to both the basic liberties and the distribution of goods. Each citizen, Rawls thinks, is entitled as a matter of basic justice to a certain set of basic liberties, together with a share of primary goods that is as equal as possible, subject to inequalities that can be justified by the difference principle.

In response to objections to the specification of the principles of justice that he offered in $A$ Theory of Justice, Rawls in Political Liberalism elaborated the political conception of the person upon which he relied, and consequently offered a refined specification of both the basic liberties and the objects of distributive justice. Persons are regarded as free and equal in virtue of their possessing to a sufficient degree the two powers

\footnotetext{
3 See John Rawls, Political Liberalism (New York: Columbia University Press, expanded ed. 1996), 144-50.

4 Ibid., 90.

5 John Rawls, A Theory of Justice (Cambridge: Harvard University Press, 1971; revised edition, 1999), 19/17 rev.
} 
of moral personality, the capacity for a sense of justice and the capacity for a conception of the good. ${ }^{6}$

The two moral powers are derived analytically from the minimal requirements of human agency and collective selfgovernment. No one can act without a conception of the good; no collectivity can fairly govern itself without some sense of justice. The constructivist procedure consists precisely in building up the conception of justice from this political conception of the person. Rawls thinks that any conception of the good that is not analytically derivable from the constructivist procedure cannot be the basis of social unity, because of the inevitable plurality of comprehensive conceptions.

In $A$ Theory of Justice, Rawls explained the priority of liberty with the claim that "liberty can be restricted only for the sake of liberty itself."7 Freeman observes that even if the scope of this demand is restricted to the basic liberties, it is implausibly strong. Restrictions on speech that prevent fraud or false advertising infringe on a basic liberty, but do not rise to the level of a human rights violation on that account. ${ }^{8}$

H.L.A. Hart persuaded Rawls that liberty is not the type of thing that can be maximized, and that $A$ Theory of Justice did not specify citizens' most fundamental interests sufficiently for this to be a workable criterion of justice. ${ }^{9}$ The idea of the moral powers provided the answer that Rawls ultimately endorsed: these liberties were to guarantee the conditions for the development and exercise of the moral powers in two "fundamental cases." The first fundamental case is connected with the capacity for a sense of justice; it is "the application of the principles of justice to the basic structure of society."10 This is the basis of the political liberties. The second fundamental case is connected with the capacity for a conception of the good; it is "the application of the principles of deliberative reason in guiding our conduct over a complete life."11 This is the basis of liberty of conscience and freedom of association.

Rawls's final position is that "a liberty is more or less significant depending on whether it is more or less

6 Political Liberalism, $103-07$.

7 A Theory of Justice, 244/214 rev.

8 Samuel Freeman, Rawls (London and New York: Routledge, 2007), 64-69. 9 Political Liberalism, 331-34, citing H.L.A. Hart, "Rawls on Liberty and Its Priority," in Norman Daniels, ed., Reading Rawls: Critical Studies of A Theory of Justice (New York: Basic Books, 1974), 230-52.

10 Political Liberalism, 332.

11 Ibid. 
essentially involved with, or is a more or less necessary institutional means to protect, the full and informed and effective exercise of the moral powers in one (or both) of the two fundamental cases."12 Freeman observes that political discussion thus deserves near-absolute protection because it is central to the exercise of the capacity for justice. ${ }^{13}$ The moral powers are protected because they are indispensable to social cooperation. ${ }^{14}$

On the other hand, in the case of behavior that does not concern "constitutional essentials and basic issues of justice," 15 it is permissible for a legislature to rely on its comprehensive conception. "Fundamental justice must be achieved first. After that a democratic electorate may devote large resources to grand projects in art and science if it so chooses."16 Thus political liberalism "does not rule out as a reason the beauty of nature as such or the good of wildlife achieved by protecting its habitat."17 As Freeman puts it, "it may well be that majority democratic decision by itself is sufficient 'public reason' for restricting conduct."18 Thus, for example, the legislature could act to "protect a dwindling and endangered species of moles that live in unspoiled prairie land that old MacDonald plans to sow in wheat."19

Rawls similarly refined his account of the primary goods that are the objects of the difference principle. The "thin theory of the good" offered in A Theory of Justice understood the primary goods as "things that every rational man is presumed to want." 20 This elicited Thomas Nagel's objection that there were no primary goods in this sense: some ways of life - religious asceticism, for instance - have no use for large amounts of wealth. ${ }^{21}$ Rawls revised his conception of primary goods in much the same way he revised his conception of basic liberties. His final position was that the primary goods are citizens' needs understood from a political point of view. According

\footnotetext{
2 Ibid., 335 .

13 Freeman, Rawls, 70.

14 Ibid., 278, 286, 343, 396.

15 John Rawls, Justice as Fairness: A Restatement (Cambridge: Harvard University Press, 2001)(hereafter Restatement), 152.

16 Ibid.

17 Ibid., 152 n. 26; see also Political Liberalism, 214-215.

18 Freeman, Rawls, 80.

19 Ibid; see also ibid., 396-97; T.M. Scanlon, "Rawls on Justification," in Samuel Freeman, ed., The Cambridge Companion to Rawls (Cambridge:

Cambridge University Press, 2003), 162-63.

${ }^{20}$ See $A$ Theory of Justice, 62/54 rev.

21 Thomas Nagel, "Rawls on Justice," in Daniels, 9-10.
} 
to the political conception, every person has higher-order interests in developing and exercising his moral powers to develop a sense of justice and a conception of the good. Justice requires "conditions securing for those powers their adequate development and full exercise." 22 The primary goods are "essential all-purpose means to realize the higher-order interests connected with citizens' moral powers and their determinate conceptions of the good (so far as the restrictions on information permit the parties to know this)." 23

The moral powers are also the basis for Rawls's conception of basic human rights. These are "a special class of urgent rights, such as freedom from slavery and serfdom, liberty (but not equal liberty) of conscience, and security of ethnic groups from mass murder and genocide." 24 These are "necessary conditions of any system of social cooperation. When they are violated, we have command by force, a slave system, and no cooperation of any kind." 25 As Freeman puts it, "[h] uman rights are regarded as the minimal freedoms, powers, and protections that any person needs for the most basic development and exercise of the moral powers that enable him or her to engage in social cooperation in any society."26 What distinguishes the basic human rights from the rights provided in justice as fairness is that the former are so fundamental that, if a government violates them, its neighbors are justified in invading its territory to put a stop to the violations. ${ }^{27}$

II. The FGM objection

A. Rawls and sex

To see the limitations of Rawls's conception of human rights, begin with his attempts to address the gay rights issue.

In $A$ Theory of Justice, he argued that justice as fairness "requires us to show that modes of conduct interfere with the basic liberties of others or else violate some obligation or natural duty before they can be restricted." In particular, ideas "that certain kinds of

\footnotetext{
22 Political Liberalism, 74.

Ibid. 76.

24 John Rawls, The Law of Peoples (Cambridge and London: Harvard University Press, 1999), 79.

25 Ibid., 68.

26 Freeman, Rawls, 436.

27 Rawls, The Law of Peoples, 78-81, 92-3 n.6.
} 
sexual relationships are degrading and shameful, and should be prohibited on this basis," are excluded. ${ }^{28}$ Thus, prohibitions of homosexual sex would violate the priority of liberty.

This conclusion, however, was derived from his premise that liberty can only be restricted for the sake of liberty. Once that premise is abandoned, a ban on homosexual relationships appears to stand on the same footing as the restriction of old MacDonald's planting. Certainly it is not necessary to be able to engage in any particular sex act in order to participate in political life.

Is sexual freedom necessary "to secure the full and informed and effective application of citizens' powers of deliberative reason to their forming, revising, and rationally pursuing a conception of the good over a complete life" ${ }^{29}$ Freeman observes that Rawls's view of liberty in his late work is less expansive than John stuart Mill's, since the idea of a central range of application for the basic liberties does not appear in Mill. ${ }^{30}$ The clearest and most forceful case of priority is liberty of conscience, the freedom to hold and communicate religious, philosophical, and moral convictions. ${ }^{31}$ But it is obscure how this extends beyond freedom of thought, to any particular action in the world that a person might want to engage in. The problem lies in the ambiguity of the moral power to form and pursue a conception of the good. In order to exercise this power, one must have a menu of choices. But this does not entail the right to have any particular option appear on the menu.

Thomas Pogge observes that Rawls's conception of the moral powers excludes any interest that is specific to some citizens and not others. The right to engage in specific conduct - Pogge uses the example of animal sacrifices - is "of very little significance to some citizens - and of great significance to others." 32 It is not clear how these rights and liberties could be mutually adjusted into a fully adequate scheme, and the effort "could also be socially divisive, as any such balancing would produce winners and losers among conceptions of the good."33 But

\footnotetext{
28 A Theory of Justice, $331 / 291$ rev.

29 Political Liberalism, 335.

30 Freeman, Rawls, 48, 78-79.

31 Ibid., 75-76.

32 Thomas Pogge, John Rawls: His Life and Theory of Justice (Oxford:

Oxford University Press, 2007), 88.

33 Ibid., 89.
} 
severe restrictions on liberty do not preclude the exercise of the moral powers. "As the case of Immanuel Kant demonstrates, it is possible (and even easier with modern communications) to develop and exercise the two moral powers without ever leaving the vicinity of one's hometown."34 Sodomy prohibitions are another illustration. They restrict some people's liberty, obviously, but others have a strong personal interest in living in the kind of society in which sodomy is unheard of, and the presence of openly gay people makes them feel like strangers in their own neighborhoods, which is not a trivial harm. ${ }^{35}$ To decide that sexual freedom is a protected liberty, the moralistic interests of some citizens would have to be balanced against the personal interests of others, and constructivism has no resources with which to perform such balancing.

Rawls holds that there is "a general presumption against imposing legal and other restrictions on conduct without sufficient reason. But this presumption creates no special priority for any particular liberty."36 The control of one's sexual intimacy is part of nearly everyone's conception of the good. But its value cannot be deduced from the moral powers. It is simply something that most people happen to value highly, and that is not enough to qualify something as a primary good:

What are to count as primary goods is not decided by asking what general means are essential for achieving the final ends which a comprehensive empirical or historical survey might show that people usually or normally have in common. There may be few if any such ends; and those there are may not serve the purposes of a conception of justice. The characterization of primary goods does not rest on such historical or social facts. While the determination of primary goods invokes a knowledge of the general circumstances and requirements of social life, it does so only in light of a conception of the person given in advance. ${ }^{37}$ In his last essay, "The Idea of Public Reason Revisited," Rawls returned to the gay rights question, writing that with respect to family law, the requirements of public reason exclude "appeals to monogamy as such, or against same-sex marriages," because such appeals "would

34 Ibid., 87.

35 See Joel Feinberg, The Moral Limits of the Criminal Law, vol. 4: Harmless Wrongdoing (Oxford: 0xford University Press, 1988), 39-80.

36 Political Liberalism, 292.

37 Ibid. , 308 . 
reflect religious or comprehensive moral doctrines." 38 Monogamy or opposition to same-sex marriage are however policy conclusions, not premises. Arguments for these conclusions might or might not reflect comprehensive doctrines. Moreover, as we have seen, comprehensive doctrines are not excluded as a basis for regulating conduct when this does not infringe on a basic liberty. How could marriage be shown to be a basic liberty in Rawls's terms? Whose moral powers are damaged by its denial? Rawls concedes, later in the same paragraph, "there might be other political values in the light of which such a specification would pass muster: for example, if monogamy were necessary for the equality of women, or same-sex marriages destructive to the raising and educating of children." ${ }^{39}$ But of course opponents of same-sex marriage, even those whose opposition rests on frankly religious grounds, always do allege exactly this. Patrick Devlin, to whom Rawls was specifically responding in $A$ Theory of Justice, ${ }^{40}$ used purely political arguments to defend the prohibition of sodomy.

A few sentences later, he puts his foot down: "arguments for considering, say, homosexual relations unworthy or degrading" are not appropriate bases for political action. "Thus, in considering whether to make homosexual relations between citizens criminal offenses, the question is not whether those relations are precluded by a worthy idea of the full human good as characterized by a sound philosophical and nonreligious view, nor whether those of religious faith regard it as sin, but primarily whether legislative statutes forbidding those relations infringe the civil rights of free and equal democratic citizens." 41 But how can he be entitled to say that? once more, why aren't gay people in this regard in exactly the same position as old Macdonald?

Since sexuality is not necessary to the exercise of the moral powers, it is not a matter of constitutional essentials. The legislature could, then, ban same-sex marriage, or even private consensual homosexual sex, on the basis of its comprehensive views. Rawls's theory offers no basis for regarding gay rights as a matter of basic justice. ${ }^{42}$

38 "The Idea of Public Reason Revisited," in Collected Papers, 587.

39 Ibid.

40 See A Theory of Justice, 331 n. 54/291 n. 53 rev.

41 "The Idea of Public Reason Revisited," 588.

42 His weakness in this regard is also noted by Carlos Ball, The Morality of Gay Rights (New York: Routledge, 2003), 22-30. 
This gap will trouble some readers less than others. Gay rights remain controversial. I therefore move on to an omission that will alarm nearly everyone. Rawls's Kantian constructivism cannot cognize the injustice of the ritual practice, common in some northern parts of Africa, of female genital mutilation (FGM). ${ }^{43}$

\section{B. Rawls and FGM}

FGM is commonly practiced on girls, sometimes as young as infancy. It almost always involves removal of the clitoris, and sometimes involves much more radical damage to the pubic area. When medical complications are avoided, 44 the consequence of FGM is often (not always) that women experience a greatly diminished capacity for sexual pleasure. ${ }^{45}$ FGM has been outlawed all over the world, ${ }^{46}$ and it is widely agreed that prohibiting the practice is a matter of basic justice for women. But this condemnation is obviously not universal. If it were, the practice would disappear. As an international statement condemning FGM

43 I use this example with acknowledgement of the danger, emphasized by Yael Tamir and acknowledged by her critics, that westerners will regard this unfamiliar practice with "smug, unjustified self-satisfaction," ignoring the abuses of women's bodies - the powerful cultural pressures that lead to breast implants, tummy tucks, botox injections, and anorexia - that are commonplace in our culture. Yael Tamir, "Hands off Clitoridectomy," Boston Review, Summer 1996; see also responses in Boston Review, Oct./Nov. 1996; Clare Chambers, "Are Breast Implants Better than Female Genital Mutilation? Autonomy, Gender Equality and Nussbaum's Political Liberalism," Crit. Rev. of Int'l Soc. \& Pol. Phil 7 (Autumn 2004): 1-33.

44 FGM is frequently performed in unsanitary conditions and may result in severe, occasionally life-threatening medical complications. As Western technology spreads, the procedure is increasingly performed by medically trained personnel with anesthesia, sterile tools, and antibiotics. See Ellen Gruenbaum, The Female Circumcision Controversy: An Anthropological Perspective (Philadelphia: University of Pennsylvania Press, 2001), 54-59, 144-49. Medical professionals perform nearly half the operations in Somalia. Carla Makhlouf Obermeyer, "Female Genital Surgeries: The Known, the Unknown, and the Unknowable," Med. Anthrop. Q. 13(1)(1999): 100 n.21. Some practices, such as infibulations, are especially likely to damage the subject's health, see Gruenbaum, 5-7, but the near-universal condemnation is not confined to those practices. Medical complications are a concern but are not at the core of the objection to FGM. I am aware of no critic of FGM who claims that it would be acceptable if performed according to normal surgical protocols.

45 There is considerable variation in the effect on women's sexual experience. Gruenbaum, 133-157.

46 See Anika Rahman \& Nahid Toubia, Female Genital Mutilation: A Guide to Laws and Policies Worldwide (London and New York: Zed Books, 2000). 
observed in 1996, "Human behaviours and cultural values, however senseless or destructive they may appear from the personal and cultural standpoint of others, have meaning and fulfil a function for those who practise them."47

FGM is not devoid of purpose. When researchers ask African women why they support the practice, they find that the women do get something out of it. ${ }^{48}$ One survey found that 82 percent of Egyptian women support a continuation of the practice. ${ }^{49}$ Some think, in accordance with long-settled cultural norms, that FGM initiates them into womanhood and their tribe. Some regard the clitoris as unhygienic and ugly. Some regard FGM as necessary to become a real woman. Some regard the practice as divinely sanctioned; some think that it is a requirement of Islam. It is often a valued marker of ethnic identity. Particularly in its more severe forms, it makes sexual intercourse difficult and so increases the likelihood that a woman is a virgin before marriage. It is also thought to enhance a husband's sexual pleasure. For these reasons, it is sometimes indispensable to a woman's marriageability, in societies in which marriage is vital to a woman's status and security. ${ }^{50}$ At least some of these are genuine goods, and the rest are strongly felt to be so. In order to reject FGM, one must argue that they are outweighed by the harm caused by the loss of sexual capacity. But that involves just the kind of balancing that, Pogge showed, Rawls was unwilling to do.

People from many different cultures agree that prohibiting the practice is a matter of basic justice for women. Yet, can Rawls say this?

47 Joint statement by the World Health Organization, UN Children's Fund (UNICEF), and UN Population Fund, February 1996, quoted in Gruenbaum, 198.

${ }^{48}$ See generally Gruenbaum; Sander L. Gilman, "'Barbaric' Rituals?," in Joshua Cohen, Matthew Howard, and Martha C. Nussbaum, eds., Is Multiculturalism Bad For Women? (Princeton: Princeton University Press, 1999), 53-58. This is ignored in the summary condemnation of FGM by Susan Okin, "Is Multiculturalism Bad for Women," in ibid., 1415, and "Reply," in ibid., 124-25. She treats FGM as if it were obvious that its only purpose is to help men control women.

49 Obermeyer, 87.

50 See Gruenbaum; Nahid Toubia, Female Genital Mutilation: A Call for Global Action (Women Ink, 1995), 35-37. This last factor suggests that many who participate in the practice might prefer to live in a world in which there were not pressure to conform to the custom, but dare not risk their daughters' economic futures by refusing to participate. See Gerry Mackie, "Ending Footbinding and Infibulation: A Convention Account," Am. Sociological Rev. 61 (1996):999-1017. But this does not mean that they are not consenting to the practice, given the circumstances in which they find themselves. 
Consider an immigrant mother who wants to have the operation performed (by a competent surgeon) on her daughter. Is there a basis in political liberalism, as formulated by Rawls, for saying that the state has an obligation to interfere with her? Does not the mother satisfy Rawls's very abstract standards of reasonableness? Rawls assumes that the family is an association "in which elders (normally parents) have a certain moral and social authority."51 The immigrant mother does not propose to tell anyone else how to raise their children. The principle that each parent gets to make value choices on behalf of their own children is a time-honored constraint on state power in free societies, one on the basis of which people could reason in common. Her comprehensive view, which entails FGM, is not an unreasonable one, and "reasonable persons will think it unreasonable to use political power, should they possess it, to repress comprehensive views that are not unreasonable, though different from their own." 52

It will not do to say simply that political liberalism aims to "secure[e] the conditions under which we can further our determinate conception of the good, whatever it is."53 FGM does not deprive its victims of their capacity to exercise their moral powers. It does not deprive them of primary goods. It removes an option, of course, but it provides other options. The value of the lost option is irrelevant for Rawls's theory, because "in establishing the fair terms of social cooperation (in the case of the basic structure) the only relevant feature of persons is their possessing the moral powers (to the sufficient minimum degree) and having the normal capacities to be a cooperating member of society over a complete life."54 Sexuality, then, is not a feature of persons that is relevant from the standpoint of basic justice. ${ }^{55}$ Rawls's constructivist procedure asks, "which traditionally

51 "The Idea of Public Reason Revisited," 596. Rawls may be more deferential to this authority than his philosophy ought to imply. See Martha Nussbaum, Women and Human Development: The Capabilities Approach (Cambridge: Cambridge University Press, 2000), 270-83. But even with much less deference, the state would need some reason to invade parental prerogatives, and constructivism cannot supply this.

52 Political Liberalism, 60.

53 Ibid., 106.

54 Ibid., 79. Doubtless Rawls himself would have thought it highly relevant, but his constructivism does not capture this concern.

55 This is also noted in Ball, 22. Martha Nussbaum observes that Rawls implicitly "make[s] personhood reside in (moral and prudential) rationality, not in the needs that human beings share with other animals." Martha Nussbaum, Frontiers of Justice: Disability, Nationality, Species Membership (Cambridge: Belknap Press, 2006), 159. 
recognized principles of freedom and equality, or which natural variations thereof, would free and equal moral persons themselves agree upon, if they were fairly represented solely as such persons and thought of themselves as citizens living a complete life in an ongoing society?"56 In order for the harm of FGM to be recognized, persons have to be represented, not solely as free and equal moral persons, but as sexual beings who have the vulnerabilities specific to such beings. FGM does not deprive its victims of their moral powers or their normal capacities for cooperation. FGM hurts them in other ways.

Rawls would clearly deem it permissible for a government to ban FGM at the legislative stage. He demands government neutrality toward conceptions of the good only with respect to the basic structure. But the prohibition of FGM is a matter of legislative discretion. It would not be required by justice. The legislature's discretion, moreover, is remarkably broad. It could rely on its comprehensive views about well-being to enact a law requiring that girls undergo FGM, in the same spirit in which states now require that children be vaccinated against disease.

\section{Rawlsian rejoinders} FGM?

Has Rawls really no resources with which to condemn

Earlier drafts of this essay have been shown to a number of distinguished scholars of Rawls, and they have been unanimous in rejecting the claim just made. This, they argue, is an easy case for him. They have not, however, agreed about why.

There are at least five Rawlsian rejoinders: Rawls condemns FGM as a kind of child abuse; (2) FGM permanently deprives girls of a valuable option, thereby restricting their equality of opportunity and capacity for moral choice; (3) FGM violates women's basic right to health; (4) FGM violates the integrity of the person; (5) FGM is an instance of gender inequality. I will take them up in turn.

(1) Child abuse. Rawls observes that "parents must follow some conception of justice (or fairness) with regard for their children," although "within certain limits, this is not for political principles to prescribe." But those

56 "Kantian Constructivism in Moral Theory," in Collected Papers, 305, emphasis added. 
limits exist: justice entails "the prohibition of abuse and neglect of children." 57 Is FGM a kind of child abuse?

This argument depends on clarifying what counts as abuse, a problem that Rawls does not explore. Within the terms of political constructivism, abuse would appear to consist in treating a child in such a way that the child fails to develop its moral powers, or is thwarted in exercising those powers as an adult.

[W] e try to answer the question of children's education entirely within the political conception. The state's concern with their education lies in their role as future citizens, and so in such essential things as their acquiring the capacity to understand the public culture and to participate in its institutions, in their being economically independent and self-supporting members of society over a complete life, and in their developing the political virtues, all this from within a political point of view. ${ }^{58}$

Persistent beatings are likely to thwart the course of moral development contemplated in Chapter 8 of $A$ Theory of Justice. Eamonn Callan has shown that Rawls's theory involves quite demanding educational requirements. Good liberal citizens must be able to distinguish disagreements which are the product of the burdens of judgment from those which merely reflect prejudice or error. ${ }^{59}$ In order to do this, they must develop a certain measure of ethical autonomy. ${ }^{60}$

In order for this argument to condemn FGM, it would have to be shown that FGM does damage the pertinent moral powers. Women who have had FGM performed upon them are, however, fully capable of being good liberal citizens.

Some of the smartest and most articulate critics of FGM are women upon whom the operation has been performed.

The root of the problem is Rawls's narrow conception of the pertinent moral powers, in which the capacity for pleasure has no place. ${ }^{61}$ Part of the explanation is probably that Rawls's work is from the beginning a reaction against utilitarianism, which makes pleasure central to moral reasoning. For Rawls, pleasure is either too private, allowing some people to claim an unfair share of

57 "The Idea of Public Reason Revisited," 598.

58 Restatement, 157.

59 Creating Citizens: Political Education and Liberal Democracy (Oxford: Oxford University Press, 1997), 24-33.

60 See ibid., 39-42, 214-20.

61 Pleasure is only made morally pertinent at one point in Rawls's work, in the discussion of the Aristotelian principle. A Theory of Justice, 426/374 rev. 
resources, or too intersubjective, failing to take seriously the distinction between persons. ${ }^{62}$ Might he share with practitioners of FGM a certain uneasiness with pleasure's potentially destabilizing power?

(2) Restricted moral capacity. FGM infringes on women's exercise of their moral powers by depriving them of a valuable option. Thus Martha Nussbaum: "Female genital mutilation means the irreversible loss of the capability for a type of sexual functioning that many women value highly, usually at an age when they are far too young to know what value it has or does not have in their own life."63 This makes sense from within the terms of Nussbaum's philosophy, at least when the operation is performed on children. ${ }^{64}$ She is no constructivist; her list of basic capabilities that should be guaranteed to everyone includes many elements that could not be deduced from Rawls's two moral powers. ${ }^{65}$ But it is not clear how anything like this can be said from within the terms of Rawlsian constructivism, which forbids a substantive judgment of the comparative goodness of different options. Eamonn Callan's Rawlsian condemnation of FGM raises a similar difficulty:

If the integrity of one's body is a precondition of personal sovereignty in sexual matters, the genital mutilation of female children in some cultures is a gross violation of their prospective interest in sovereignty. The practice is indefensible because it cannot be squared with the moral equality of the child's prospective interest and the adult's realized interest in a zone of personal sovereignty. ${ }^{66}$

Rawls, however, has no basis for singling out "personal sovereignty in sexual matters" as particularly

62 Bonnie Honig suggested to me that Rawls, in his determination to move beyond utilitarianism, may have failed to appreciate the importance of pleasure to human moral life.

63 Martha Nussbaum, "Judging Other Cultures: The Case of Genital Mutilation," in Sex and Social Justice (Oxford: Oxford University Press, 1999), 124.

64 It is less clear that Nussbaum can condemn the operation when performed upon adults. See Chambers.

65 The list of capabilities appears in many of Nussbaum's writings. One recent version is Frontiers of Justice, 76-78. Its elements include the ability to live a life of normal duration, the ability to have good health, the ability to move about freely, freedom from violence, reproductive choice, the ability to imagine, think and reason, the ability to laugh and play, political and property rights on an equal basis with others, and many other things.

${ }^{66}$ Callan, 147. Callan does not discuss male circumcision or earpiercing. 
important. The outlawing of FGM for girls does not preserve all options. It closes off one option while opening up others. Once more, it is not clear how the basic moral power to have and pursue a conception of the good entails the right to do anything in particular. Equality of opportunity only matters if the opportunity being foreclosed is indeed a valuable one.

Another formulation of this rejoinder would begin by noting that all citizens are entitled to revise their conceptions of the good (in ways that are compatible with the right). This puts limits on the ways a parent can treat his children - - a father cannot so restrict the choices of his daughter that she cannot make up her own mind about the kind of life to live. FGM in childhood often makes it impossible for a daughter, once she reaches adulthood, to enjoy her sexuality. ${ }^{67}$

This rejoinder would only have force if the child's capacity to revise her conception of the good were being impaired for no reason at all. Then there would be a loss of opportunity to exercise the moral powers with nothing at all to compensate for it. However, as we have seen, this is not true of FGM.

(3) The right to health. It may also be claimed that FGM damages a girl's health. This cannot refer to the danger of infection from the procedure - as noted above, that can be controlled by performing it competently under sterile conditions - but the impairment of sexual

functioning. A healthy person has capacities that are harmed by FGM.

"Health," however, is a contested concept. Sickness is deviancy from a norm. The norm is not given by nature. The "blight" that strikes corn is labeled a disease because humans want the corn crop to survive; otherwise we would just talk about the competition between two species. ${ }^{6}$ Health is simply a desirable state of affairs. I agree that FGM is damaging to a girl's health, but only because I think that the capacity to orgasm is desirable - a conclusion that can't be derived from Rawlsian constructivism. Rawls writes that the right to medical care "falls under the general means necessary to underwrite fair equality of opportunity and our capacity to take advantage of our basic rights and liberties, and thus to be normal and cooperating members of society over a complete

67 Thanks to Richard Kraut for this formulation.

68 See Ronald Bayer, Homosexuality and American Psychiatry: The Politics of Diagnosis (Princeton: Princeton University Press, rev. ed. $1987), 183-86$. 
life." 69 This is the source of the "urgency" of "treatment that restores persons to good health, enabling them to resume their normal lives as cooperating members of society."70 But FGM does not impair women's ability to be cooperating members of society. Condemning FGM on the basis of "health" is a cheat, because it assimilates a controversial conception of well-being to an uncontroversial one, and then relies on the uncontroversial one to do the normative work.

(4) The integrity of the person. We already noted Callan's claim that FGM violates "the integrity of one's body."71 Rawls lists "integrity of the person" among the basic liberties. ${ }^{72}$ But there must be limits to this. It must be permissible to perform necessary surgery on children, for example. Does unnecessary surgery count as a violation of the integrity of the person? What counts as "unnecessary" is of course deeply contested. Few people are upset by cosmetic surgery for children to eliminate medically harmless, but socially stigmatizing, deformities. (It seems strange to us that North Africans regard the clitoris as a deformity, but reduction surgery is routinely performed in the United States on female infants with unusually large clitorises.) Many Americans pierce the ears of their daughters (but not their sons) to accommodate earrings; this goes almost completely unremarked. Male circumcision has not produced anything like the condemnation that FGM has provoked, because its ritual significance is more widely appreciated and its effect on sexual pleasure is much more uncertain. Do these practices violate fundamental human rights? If a well-ordered society has a neighbor where the piercing of young girls' ears is customarily practiced and tolerated by the state, would military intervention be warranted?

When Rawls cites the integrity of the person, he most obviously has in mind violations of bodily integrity, such as assault or torture, that impair the exercise of the moral powers. As we have already seen, FGM does not do this. Since it does not, the Rawlsian right of integrity cannot extend this far.

(5) Gender inequality. Rawls might also condemn FGM as a variety of gender inequality. The practice is only done to women, it harms women, and it exists for the sake of satisfying male concerns about female chastity and male

\footnotetext{
69 Restatement, 174.

70 Ibid.

71 Callan, 147.

72 Political Liberalism, 291.
} 
pleasure. But, again, this only works if what's lost is valuable. Ear-piercing and male circumcision are also sexspecific marks of inequality that reinforce traditions of female subordination. If one is looking for sex-specific practices that violate Rawlsian justice, FGM is less objectionable than the Western practice of enlarging women's breasts with silicone implants - a procedure that is usually performed on consenting adults, but in response to social pressures that are often experienced as crushing. The harms caused by implants include chronic pain and an increased likelihood of early death, since the implants make it harder to detect incipient breast cancer. ${ }^{73}$ These obviously compromise any exercise of the moral powers. Once more, as with children, it is only interference with the moral powers that raises fundamental issues of justice. "The equal rights of women and the basic rights of their children as future citizens are inalienable and protect them wherever they are. Gender distinctions limiting those rights and liberties are excluded."74 The italics are mine, and the italicized language is restrictive. Since FGM does not impair women's rights and liberties as citizens, it does not violate basic justice. It may also be said that FGM is unjust because it is only done to women, and thus rests on a view that the deprivation of sexual pleasure is trivial if it happens to women, but not to men. Such a view obviously treats women less respectfully than men. This response however implicitly relies on the assumption, which we have seen is unavailable to the Rawlsian constructivist, that sexual pleasure is something that matters a lot. Once more, other gender-asymmetrical burdens, such as the denial to Jewish males of the sensations of sex with a foreskin, are less troubling. 75

IV. The knife in the clam

How big a problem is constructivism's inability to address FGM? It depends on how important it is to exclude nonconstructivist ideas of the good from our conception of justice. Rawls fears that such nonconstructivist ideas cannot be the basis of social unity. In this, we can now conclude, he is too pessimistic. There is an impressive amount of agreement about FGM, even though constructivism lacks the resources to condemn it.

73 See Chambers, 23.

74 "The Idea of Public Reason Revisited," 599.

75 Thanks to Anthony Laden for pressing me on this point. 
The source of the pessimism, for Rawls, is the experience of inevitable pluralism. "Our individual and associative points of view, intellectual affinities, and affective attachments, are too diverse, especially in a free society, to enable those doctrines to serve as the basis of lasting and reasoned political agreement."76 For this reason, justice cannot depend on any comprehensive conception.

There is a revealing slippage in Rawls's understanding of what a comprehensive conception is. A conception is comprehensive, Rawls explains, "when it includes conceptions of what is of value in human life, and ideals of personal character, as well as ideals of friendship and of familial and associational relationships, and much else that is to inform our conduct, and in the limit to our life as a whole."77 "A conception is fully comprehensive if it covers all recognized values and virtues within one rather precisely articulated system."78 There cannot be social consensus around such fully comprehensive conceptions. ${ }^{79}$

However, Rawls also relies on a much more peculiar notion, that of a "partially comprehensive" conception, which comprises "a number of, but by no means all, nonpolitical values and virtues and is rather loosely articulated." 80 This is an odd locution. It is like saying that a person with a speck of dirt on his shoulder is partially buried. Evidently "comprehensive" refers to any conception of the good not derivable from constructivism, even if it is itself not very comprehensive at all. ${ }^{81}$

\footnotetext{
76 Political Liberalism, 58.

77 Ibid., 13.

78 Ibid.

79 Ibid., 61.

80 Ibid. , 13.

81 Ruth Abbey uses the comprehensive/noncomprehensive distinction in a different way. For her, a conception is comprehensive if it has implications outside the sphere that is conventionally deemed political. "It is unclear what remains of a strictly political conception [if, as Rawls states in his late work, ] there is no domain or space immune from the principles of justice. What does a purely political liberalism demarcate if its principles penetrate all (or most) aspects of life?" Ruth Abbey, "Back toward a Comprehensive Liberalism? Justice as Fairness, Gender, and Families," Political Theory 35 (2007): 17. For this reason, she thinks that Rawls embraces a comprehensive liberalism as soon as he holds that principles of justice apply to relations within families. Rawls's answer would be that liberalism is political, even when it regulates the family, because its only concern is to protect the exercise of the moral powers in the fundamental cases. Other concerns are excluded. Rawls always regarded the family as part of the basic structure. See Martha $\mathrm{C}$.
} 
Are "partially comprehensive" conceptions impossible bases of social unity? Consider one possibility: a political liberalism that guarantees to everyone the opportunity to exercise the moral powers, but also opportunities for sexual satisfaction, at least via heterosexual intercourse within marriage. In other words, Rawls's constructivism with one tiny bit added. Call it $C+S$ (constructivism plus sex). The addition of that tiny bit makes $\mathrm{C}+\mathrm{S}$ into a partially comprehensive conception. Why would one think that this diminishes the prospects for social unity? It rather seems to increase the likelihood of social unity, at least compared with constructivism, since so many people are persuaded that FGM violates basic justice.

The real problem is that the bit that has been added is not derived from the moral powers, in the way the other goods on the list were. It lacks constructivist credentials. Once the bouncer has let this patron in, the lack of such credentials can no longer be a principled reason to exclude others. If there is such a reason, it can't be derived from constructivism. The addition of FGM is not like a small additional wing on the constructivist building. To vary the metaphor, it is more like a knife in a clam. Once the blade gets in, the clam has no resources left for keeping anything else out.

Rawls evidently thinks that pure constructivism is the only reliable path to social unity. In modern societies, there is so much normative pluralism that the only overlapping consensus that is consistent with respectful relations is that constructed without any reference to the actual normative views of members of society. That is why "partially comprehensive" views must be excluded. Political liberalism, he argues, should be freestanding, so that it "can be presented without saying, or knowing, or hazarding a conjecture about, what [comprehensive] doctrines it may belong to, or be supported by."82 "[T]he political conception of justice is worked out first as a freestanding view that can be justified pro tanto without looking to, or trying to fit, or even knowing what are, the existing comprehensive doctrines." 83 This approach may

Nussbaum, "Rawls and Feminism," in The Cambridge Companion to Rawls, 500-03 (collecting pertinent passages in Rawls's work).

82 Political Liberalism, 12-13.

83 John Rawls, "Reply to Habermas," J. Phil. 42 (1995): 145. For similar formulations, see Political Liberalism, xlvii; "The Idea of Public

Reason Revisited," 585; Restatement, 37, 188-89. T.M. Scanlon explains why the strategy of surveying actual comprehensive views would not be satisfactory to Rawls. "It would be impossible to survey all possible 
possibly work under certain circumstances, but they are likely to be as unusual as the circumstances in which it is safe to drive a car while blindfolded.

Rawls aspires to "civic friendship," in which we the citizens exercise power over one another on the basis of "reasons we might reasonably expect that they, as free and equal citizens, might reasonably also accept."84 In order for people to be "reasonable where others are concerned," Rawls writes, they must be "willing to govern their conduct by a principle from which they and others can reason in common."85 Citing and paraphrasing the more fully elaborated view of Thomas Scanlon, Rawls writes that in order to be reasonable, we should want "to be able to justify our actions to others on grounds they could not reasonably reject - reasonably, that is, given the desire to find principles that others similarly motivated could not reasonably reject." 86 Comprehensive doctrines can reasonably be rejected. "Since there are many reasonable doctrines, the idea of the reasonable does not require us, or others, to believe any specific reasonable doctrine, though we may do so."87

This formulation carries with it some of the difficulties of Scanlon's own view. Unity with others may be attractive, but we give up on that as soon as we decide that what matters is what they would accept were they reasonable, rather than what they actually accept. Scanlon's criterion of ideal justifiability, Colin McGinn observes, "effectively surrenders the idea that morality necessarily involves unity with others - actual unity, I

comprehensive views and inadequate, in an argument for stability, to consider just those that are represented in a given society at a given time since others may emerge at any time and gain adherents." "Rawls on Justification," 164. On the other hand, a consensus built around the convergence of a contingent set of actual views may last a long time.

84 "The Idea of Public Reason Revisited," 579.

85 Political Liberalism, 49 n.1.

86 Ibid., 49 n.2, citing T.M. Scanlon, "Contractualism and Utilitarianism," in Amartya Sen \& Bernard Williams, eds., Utilitarianism and Beyond (Cambridge: Cambridge University Press, 1982). This concern about what it is reasonable to expect people to accept goes back to Rawls's early writings. See John Rawls, "Justice as Fairness," in Collected Papers, 59. Freeman observes that the historical order of influence is from Rawls to Scanlon. Justice and the Social contract, 93, 148.

87 Political Liberalism, 60. 
mean. For what is the point of unity with purely hypothetical others?"88

Rawls's aspiration is similarly hypothetical. "[0]ur exercise of political power is fully proper only when it is exercised in accordance with a constitution the essentials of which all citizens as free and equal may reasonably be expected to endorse in the light of principles and ideals acceptable to their common human reason." 89

This hypothetical aspiration is still present even in Rawls's last, somewhat chastised conception of the possibility of social unity. Rawls eventually acknowledged that there is "a family of reasonable though differing liberal political conceptions."90 Even if Rawls's basic framework is accepted, "there are indefinitely many considerations that may be appealed to in the original position and each alternative conception of justice is favored by some considerations and disfavored by others."91 Freeman observes that the concession that there will not be general agreement on justice as fairness "must have been an enormous disappointment to him, for he had worked for nearly forty years trying to show how a well-ordered society where everyone accepts justice as fairness as its public charter is a realistic possibility . . . . "92

The family of reasonable conceptions still evidently includes only those that can arguably satisfy Scanlonian standards. For any of these conceptions, "when terms are proposed as the most reasonable terms of fair cooperation, those proposing them must think it at least reasonable for others to accept them, as free and equal citizens, and not as dominated or manipulated or under pressure caused by an inferior political or social position."93 As Freeman puts it, "[e]ven if reasonable and rational democratic citizens cannot agree on the same conception of liberal justice not to mention the most reasonable conception for Rawls, justice as fairness - all are under a duty to propose and

\footnotetext{
88 Colin McGinn, "Reasons and Unreasons" (review of T.M. Scanlon, what We Owe to Each Other), New Republic, May 24, 1999, 37. Similar objections have been raised by Jurgen Habermas and Cristina Lafont. Jurgen Habermas, "Reconciliation Through the Public Use of Reason: Remarks on John Rawls's Political Liberalism," J. Phil. 42 (1995): 122; Cristina Lafont, "Moral Objectivity and Reasonable Agreement: Can Realism Be Reconciled with Kantian Constructivism?", Ratio Juris 17:1 (2004): 27-51.

89 Political Liberalism, 137, emphasis added.

90 Ibid., xxxviii. See also "The Idea of Public Reason Revisited," 582.

91 Rawls, Restatement, 133.

92 Freeman, Rawls, xiii.

93 The Law of Peoples, 14.
} 
support laws that they can reasonably expect other citizens can reasonably endorse in their capacity as free and equal citizens." 94 The aspiration to hypothetical agreement remains a regulatory norm even after it is admitted that the aspiration for actual agreement is forlorn.

The reasonableness here is not the reasonableness of prediction, the way we ask whether it's reasonable to think that you can get that jalopy to start on this frigid morning. It is not a claim about what it is probable that the citizens of a society will endorse. Rather, it is a claim about what it is reasonable to ask them to endorse. The payoff may then be, not social unity, but confidence in our own righteousness as we gird for political warfare. If the demands of constructivism are reasonable, but our fellow citizens do not in fact endorse them, then that is their fault and not constructivism's. We may not be able to have unity with them, but we can have unity with hypothetical reasonable others.

A more charitable reading would understand Rawls and Scanlon as making proposals, proffering terms of cooperation that are a possible basis for community among persons with differing views. "Putting people's comprehensive doctrines behind the veil of ignorance enables us to find a political conception of justice that can be the focus of an overlapping consensus and thereby serve as a public basis of justification in a society marked by the fact of reasonable pluralism." 95 The path to actual civic friendship leads through reasonable terms of cooperation. ${ }^{96}$

If what you want is unity with actual others, however, you had better learn what those others think before you start proposing terms of cooperation with them. Rawls's answer, abstracting away from all comprehensive views, is problematic from his own perspective if the regime it produces so alienates some citizens that they no longer feel themselves part of the political community. The consequences of excluding "partially comprehensive" views may be unacceptable to some. If, as I have argued,

94 Freeman, Rawls, 379. See also "The Idea of Public Reason Revisited," 578; Burton Dreben, "On Rawls and Political Liberalism," in The Cambridge Companion to Rawls, 338-39.

95 The Law of Peoples, 32.

96 That the aim is to contain disagreement within a framework of mutual respect is particularly clear in T.M. Scanlon, "The Difficulty of Tolerance," in David Heyd, ed., Toleration: An Elusive Virtue (Princeton: Princeton Univ. Press, 1998), 226-39, which is cited with approval in Rawls, "The Idea of Public Reason Revisited," 588 n.42. 
constructivism cannot cognize atrocities such as FGM, they may even be unacceptable to you.

of course, if a thicker conception of the good than that imagined by constructivism is integral to the basic structure of the regime, that will alienate some people, too. The immigrant mother considered earlier, for example. You're going to have political alienation whatever you do. ${ }^{97}$ It can't be eliminated. But it can be minimized. One can try to have as small a remainder of alienated people as one can manage. And even with respect to them, the regime will be a good deal less brutal if it understands that remainders are inevitable. ${ }^{98}$ The task of achieving that is a prudential one, involving practical consequential judgments. The problems it raises are not resolvable from the standpoint of high theory. Constructivism is one possible solution, perhaps suitable for a society that faces a maximum of moral disagreement. But that does not appear to be our situation.

The question with which Rawls begins is still the right question to ask: "how is it possible for there to exist over time a just and stable society of free and equal citizens, who remain profoundly divided by reasonable religious, philosophical, and moral doctrines?"99 Rawls's response is political liberalism. Constructivism of the kind he contemplates is part of any possible answer; a system that denies some people the opportunity to exercise their moral powers in the fundamental cases is not a system of cooperation at all. ${ }^{100}$ (I regard the present article as a friendly amendment to Rawls.) But must political liberalism stop there? The answer depends on what counts as political liberalism. Perhaps Rawls's understanding of the demands of political liberalism is too stringent, so that conceptions that may in fact be attractive bases for social unity, such as C+S, are unnecessarily excluded.

97 Steven D. Smith, "Symbols, Perceptions, and Doctrinal Illusions: Establishment Neutrality and the 'No Endorsement' Test," Mich. L. Rev. 86 (1987): 266-332; David M. Smolin, "Regulating Religious and Cultural Conflict in Postmodern America: A Response to Professor Perry," Iowa L. Rev. 76 (1991): 1067-1104.

98 See Bonnie Honig, Political Theory and the Displacement of Politics (Ithaca and London: Cornell University Press, 1993).

99 Political Liberalism, 4.

100 For an elaboration of human rights on this kind of basis, see James Griffin, On Human Rights (Oxford: Oxford University Press, 2008). Griffin's work contains many valuable insights, but it is as incomplete as Rawls; it is unclear how his approach could defend a right against FGM. 
In order for a conception of justice to be political, Rawls writes, three conditions must be satisfied: it must apply solely to the basic structure of society, be independent of any wider comprehensive doctrine, and be elaborated in terms of ideas implicit in a society's public political culture. ${ }^{101}$ Given his broad definition of what counts as a wider comprehensive doctrine, this seems to permit only some variety of constructivism. Anything else, such as $\mathrm{C}+\mathrm{S}$, violates the second condition.

If one wants an overlapping consensus without constructivism, then it will not do simply to remove Rawls's second condition. That lets in far too much. So the criteria for political liberalism must be revised altogether.

The kind of wholesale revision that I am suggesting has already been undertaken, unannounced, in the recent work of Martha Nussbaum. Nussbaum claims that she is a "political liberal," and says that in this she is following Rawls. ${ }^{102}$ However, she justifies this label for her own, capabilities-based conception of justice on very different grounds than Rawls relies upon: (1) it is openended and subject to revision; (2) its terms are specified in an abstract way; (3) it is "freestanding" in that it is not grounded in any particular moral conception; (4) it emphasizes capability and not functioning, so that people can choose whether to exercise any particular capability; (5) the major liberties that protect pluralism, such as freedom of speech, are central on the list; (6) it is not a basis for intervention in the affairs of other states, absent crimes against humanity. ${ }^{103}$

Nussbaum silently abandons Rawls's constructivist sense of "freestanding," by which he means that a conception "can be presented without saying, or knowing, or hazarding a conjecture about, what [comprehensive] doctrines it may belong to, or be supported by."104 For Nussbaum, "freestanding" means that a conception "does not contain any particular metaphysical or epistemological doctrine, and can be rendered compatible with the major ones that citizens may hold."105 It is obviously a good

101 Ibid., 223; "The Idea of Public Reason Revisited," 584.

102 Martha C. Nussbaum, "Political Objectivity," New Lit. Hist. 32 (2001): 883-906.

103 Frontiers of Justice, 78-80, 296-98.

104 Political Liberalism, 12-13.

105 "Political Objectivity," 891. Elsewhere, she uses "freestanding" even more loosely, to refer to any intuition about value that is unconnected with a larger philosophical system. Women and Human Development, 76, 83; Frontiers of Justice, 279, 280, 370. 
deal easier to satisfy Nussbaum's requirement than Rawls's. Many partly comprehensive views could meet Nussbaum's criteria; none could meet Rawls's. ${ }^{106}$

It is unsurprising, then, that Linda Barclay disputes Nussbaum's claim to be a political liberal. Barclay has argued that the controversial goods on Nussbaum's capabilities list show that Nussbaum is not a political liberal at all, but rather has formulated a distinctive kind of comprehensive liberalism, "a theory that takes as its most central value the realisation of each individual's capacity to choose and pursue their own conception of the good life."107 Nussbaum responds by acknowledging the controversial elements of her conception, but (here silently reducing the six characteristics above to the single most important one) she insists that her conception is still "acceptable to people holding many different views of life."108 This criterion is responsive to the needs of a pluralistic society, but it is also less formal and, more importantly, less demanding than that laid down by Rawls. If Nussbaum is a political liberal, it is because she has redefined political liberalism in a way that makes the club of political liberals easier to get into. This move is objectionable if and only if pure constructivism, of the kind that Rawls offers, is the best way to respond to the fact of pluralism.

There is a certain ipse dixit quality to Nussbaum's capabilities list: none of the elements are argued for; she simply hopes that the reader will agree that these are necessary elements of a decent human life. ${ }^{109}$ She is, at

106 Rawls rejects, as "political in the wrong way," a conception of the primary goods according to which we "look at the various comprehensive doctrines actually found in society and specify an index of such goods so as to be near to those doctrines' center of gravity, so to speak; that is, so as to find a kind of average of what those who affirmed those views would need by way of institutional claims and protections and all-purpose means." Political Liberalism, 39. This may, however, be an accurate description of Nussbaum's procedure.

107 Linda Barclay, "What Kind of Liberal is Martha Nussbaum?," Sats Nordic Journal of Philosophy 4 (2003): 17.

108 Martha C. Nussbaum, "Political Liberalism and Respect: A Response to Linda Barclay," Sats - Nordic Journal of Philosophy 4 (2003): 29; see also Women and Human Development, 74.

${ }_{109}$ Freeman observes that Nussbaum's capabilities list "is largely expositive; there is little detailed argument for the items on her list and nothing resembling a constructivist procedure like Rawls's original position to connect her principles of justice with an ideal of persons and society." Samuel Freeman, "Frontiers of Justice: The Capabilities Approach vs. Contractarianism," Tex. L. Rev. 85 (2006): 391. Nussbaum writes that with respect to each item on her list, "an intuitive argument must be made that a life without a sufficient level of each of 
the same time, cautious about saying too much. Thus she is not even willing to say that the exercise of the capabilities is good, since that does not show enough respect for those who disagree. ${ }^{110}$ This effort to be just barely specific enough is a delicate one. It is not clear how one can valorize a capability without valorizing what the capability is for. ${ }^{111}$ But if the execution of her project generates puzzles, the project itself is the right one to undertake: to minimize the remainder, while taking a stand on those matters with respect to which she is unwilling to budge.

$\star$

I noted at the outset that constructivism has two attractions: it provides a secure foundation for human rights, and it makes possible a kind of civic unity in the face of intractable differences about what is good. It should now be clear that both of these selling points need to be qualified. Constructivism provides a foundation for some rights, but others equally urgent will require support from some other source. The civic unity constructivism offers may not be the most inclusive unity available in our society.

What can we say about the intractability of disagreement about the human good? Sometimes goods can be bad. Different people have different ideas about what makes a life good, and these differences may make it hard to live together in a mutually respectful way. Introducing controversial conceptions of the good into politics can have pernicious consequences. It is necessary somehow to contain goodness. Rawls's constructivism attempts to filter out bad goods. But, as we have seen, it filters out too much; it is unable to cognize some goods that are intensely relevant to questions of justice.

It is sometimes appropriate to define some good, for political purposes, at a high level of abstraction, so that it incorporates unorthodox as well as conventional variants. The state will then be neutral among those variants, and so filter out conceptions of the good that

these entitlements is a life so reduced that it is not compatible with human dignity." Frontiers of Justice, 278-79.

110 See Martha C. Nussbaum, Liberty of Conscience: In Defense of America's Tradition of Religious Equality (New York: Basic Books, 2008), 168-69.

111 Kimberly A. Yuracko, Perfectionism and Contemporary Feminist Values

(Bloomington: Indiana U. Press, 2003), 41-46; Barclay, 15-16. 
are inappropriately specific. But whether this is so in any particular case will depend on the reasons for abstraction that obtain in that particular case. ${ }^{112}$

The opening of discourse on justice to partly comprehensive views is not a prescription for civil peace. It means that there will be endless contestation and negotiation about the kind and degree of neutrality we will have. Rawls concludes his final book with the sober reflection that if his political ideal of reasonableness cannot be realized, "[i]f . . .human beings are largely amoral, if not incurably cynical and self-centered, one might ask, with Kant, whether it is worthwhile for human beings to live on the earth."113 But these are not the only possibilities. It is possible that the specific terms of reasonable cooperation proposed by Rawls are not feasible, but that human beings nonetheless continue to strive for respectful cooperation, albeit on different terms than Rawls proposes. That striving, in a context of continuing disagreement about justice, is not the constructivist vision of social unity. But it may be "the deepest and most reasonable basis of social unity available to us as citizens of a modern democratic society."114

112 See Andrew Koppelman, "The Fluidity of Neutrality," Rev. Pol. 66 (2004): 633-48.

113 The Law of Peoples, 128.

114 "Reply to Habermas," 146. 